\title{
ДОСТУП К ИНФОРМАЦИИ О ДЕЯТЕЛЬНОСТИ ОРГАНОВ ГОСУДАРСТВЕННОЙ ВЛАСТИ И МЕСТНОГО САМОУПРАВЛЕНИЯ
}

\begin{abstract}
Аннотация: Статья посвящена исследованию вопроса доступа к информации о деятельности органов государственной власти и местного самоуправления. Раскрыто содержание такой формы реализации конституционного права на информацию как доступ кинформации, посредством которого человек игражданин способен удовлетворить потребность в получении интересующей информации как непосредственно через официальные источники, так и путем направления запроса и получения на него ответа из органа государственной власти и (или) местного самоуправления. В работе изучен вопрос открытости органов власти и местного самоуправления, в результате чего сделан вывод о том, что открытость способствует наибольшей реализачии конституционного права на информачию, позволяет сохранять баланс интересов государства и отдельного человека и гражданина в условия информачионного общества. В работе предложено авторское понимание доступа к информации, предложена концепиия Федерального закона «О праве на информацию», рассмотрены вопросы правореализии конституционного права на информацию через доступ к информации, в рамках которого обозначены не только ограничения данного права, устанавливаемые законодателем, но и пределы реализачии права.

Abstract: This article investigates the issue of access to information about the activities of government and municipal government authorities. It considers the substance inherent in the exercise of this type of constitutional right to information, such as access to information. This right allows a person and a citizen to satisfy his need to obtain the required information either directly from official sources or by sending a request and receiving an answer from the state or local government authority. This article considers the issue of transparency of state and local government bodies, and concludes that openness is the major contributor to the exercise of the constitutional right to information. It maintains a balance between the interests of the state and the individual and the citizen in the framework of the knowledge society. The author proposes a new concept of access to information as well as insights into the federal law 'On access to information on activities of state bodies and local government bodies'. He considers issues relating to the legal exercise of the constitutional right to information through access to information, detailing not only the limitations of this right as set by the legislator, but also limits to the exercise of the right. Ключевые слова: право на информаиию, конституиионное право, доступ к информации, приниип открытости, органы государственной власти, государство, права человека, обязанности должностных лии, ответственность, право Keywords: right to information, constitutional law, access to information, principle of transparency, government bodies, government, human rights, obligations of administrative officials, accountability, rights
\end{abstract}

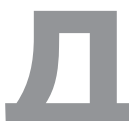

оступ к информации о деятельности органов государственной власти и местного самоуправления в настоящее время является одним из основных способов реализации человеком и гражданином своего конституционного права на информацию, хотя еще совсем недавно отсутствовало не только понимание данного права, но и его нормативное закрепление.

Так, в 9 февраля 2009 года Государственной Думой Федерального Собрания Российской Федерации при- нимается Федеральный закон N 8-Ф3 «Об обеспечении доступа к информации о деятельности государственных органов и органов местного самоуправления», который положил начало процессу обеспечения конституционного права человека и гражданина на информацию о деятельности органов государственной власти и местного самоуправления посредством доступа к ней.

Однако, общей методологической проблемой данного Закона до настоящего времени, на мой взгляд, является использование термина «доступ», через раскрытие 
которого мы обращаемся к содержанию, закрепленных в ч.4 ст. 29 Конституции Российской Федерации правомочий по реализации конституционного права на информацию через её поиск и получение. Это означает, что лицо вправе искать и получать информацию, а органы обязаны ее предоставить. Вопрос с пониманием такой правовой категории как «доступ к информации» законодателем не раскрыт.

Изучая вопросы необходимости, актуальности такой правовой категории как «доступ к информации» мы пришли к некоторым выводам.

Так, во-первых, отметим, что важным условием осуществления доступа к информации, соблюдения баланса ограничения права на доступ к информации и права на получение информации является реализация принципа открытости органов государственной власти, поскольку информация об их деятельности является предметом анализа и оценки общественности ${ }^{1}$.

Получение официальной информации является способом увеличения прозрачности деятельности органов власти, и потому на государствах лежит обязанность по обеспечению систематического доступа граждан любыми способами, в том числе и через электронные средства коммуникации, ко всем документам, которые по закону являются общественным достоянием ${ }^{2}$.

Согласно Конституции Российской Федерации для обеспечения конституционного права на информацию органы государственной власти обязаны: опубликовывать законы и иные нормативные акты, затрагивающие права, свободы и обязанности человека (ч. 3 ст.15), обеспечивать каждому возможность ознакомления с документами, материалами, непосредственно затрагивающими права и свободы лица (ч.2 ст.24), обнародовать факты и обстоятельства, создающие угрозу для жизни и здоровья людей (ч.3 ст.41).

Посредством реализации данных обязанностей граждане имеют доступ к получению информации о деятельности органов государственной власти и местного самоуправления через открытые источники информации. Однако, проблема достоверности данной информации, ее актуальности в определенный промежуток времени остается по-прежнему острой.

Дело в том, что до настоящего времени отсутствует не только контроль за достоверностью предоставляемой информации, своевременностью ее предоставления и ее

\footnotetext{
${ }^{1}$ Малько А.В., Исаков Н.В., Субочев В.В. Правовая политика в урегулировании лоббизма. Саратов. 2003. С.56.

2 Бачило И.Л. Информационное право: актуальные проблемы теории и практики: колл.монография.М., 2009. С.59-60.
}

актуальностью, но и в самих государственных органах и органах местного самоуправления не определены лица, ответственные за предоставление информации, что, безусловно, требует изменений.

Во-вторых, вопрос обеспечения доступа к информации урегулирован конституционным законодательством, но это всего лишь рамочное регулирование, которое должно найти свое дальнейшее закрепление в отраслевом законодательстве и не только в Федеральном законе N 8-Ф3 «Об обеспечении доступа к информации о деятельности государственных органов и органов местного самоуправления», чего до настоящего времени в полной мере не сделано, хотя, как замечает Монахов В.Н. «импульс данному праву уже дан во многих демократических странах, где оно понимается как право на доступ к нормативным и фактическим правительственным источникам»³.

В третьих, согласно ч.2 ст.24 Конституции Российской Федерации закрепляется обязанность органов государственной власти и органов местного самоуправления, их должностных лиц обеспечивать каждому возможность ознакомления с документами и материалами, непосредственно затрагивающими его права и свободы. В данном случае к праву на доступ к информации применена зеркальная форма его отражения в конституционном тексте через обязанность ответственных за реализацию субъективного права лиц, а также как при провозглашении субъективного права всегда имеется ввиду корреспондирующая ему обязанность государственных органов и других субъектов права, так и здесь обязанность органов государственной власти корреспондирует праву граждан.

В четвертых, право на доступ к информации закреплено не в ч. 4 ст.29 Конституции Российской Федерации, где перечислены все основные формы реализации субъективного права человека и гражданина на информацию, такие как поиск, получение, передача, производство и распространение информации, а в отдельной статье Конституции России, что подчеркивает его как самостоятельную форму реализации конституционного права на информацию, связывая данную форму непосредственно с доступом к информации о деятельности органов государственной власти. Кроме того, по смыслу ч.3 ст.41 и ст.42 Основного закона каждый имеет право на доступ к информации о фактах и обстоятельствах, создающих угрозу для жизни и здоровья людей, а также право на информацию о состоянии

\footnotetext{
${ }^{3}$ Монахов В.Н. Государственно-правовые вопросы информационного обслуживания граждан в СССР (конституционный аспект): Автореф...дис. канд. юрид. наук. М., 1983. С.15-16.
} 
DOI: $10.7256 / 1811-9018.2013 .11 .9677$

При цитировании этой статьи сноска на dоі обязательна

\section{Право и политика $11(166) \cdot 2013$}

окружающей среды. Управомоченными субъектами, в силу ч. 2 ст. 24 Конституции России, на предоставление такой информации, выступают государственные органы власти и местного самоуправления.

Распространено мнение, что государство обеспечивает право человека и гражданина на доступ к информации путем непосредственного предоставления документов и материалов заинтересованным лицам, в том числе сведений, основываясь на которые принятые те или иные решения государственными органами и органами местного самоуправления, а также путем опубликования официальной информации ${ }^{4}$. Часть 3 статьи 15 Основного закона направлена как раз на осуществление данной возможности и имеет непосредственное отношение к проблеме доступа граждан к официальной информации, в том числе правового характера. «Законы,- сказано в ней,-- подлежат официальному опубликованию. Неопубликованные законы не применяются, ... если они не опубликованы официально для всеобщего сведения».

В связи с изложенным, например В.Н.Монахов, к данному праву также относит правомочие на свободный доступ к информации о ходе законодательного процесса (в соответствии с ч.2 ст.100 Конституции заседания Совета Федерации и Государственной Думы являются открытыми $)^{5}$. В этом же ряду расположено информационное правомочие каждого на свободу поиска и получения информации о ходе осуществления судебной власти, обеспеченное ч. 1 ст.123 Конституции России.

Однако, изучая вопрос реализации конституционного права на информацию, а именно такой его формы как доступ к информации, нами сделан вывод о том, что абсолютного права на доступ к информации не может быть в силу установленных нормативно-правовыми актами, правовых ограничений правомочий по реализации исследуемого конституционного права, нарушение которых должно с неизбежностью приводить к наступлению ответственности.

В этой связи С.С. Алексеевым ${ }^{6}$ отмечалось, что «назначение права заключается не в том, чтобы «предписывать» поведение людей (как это происходит при запретительно-предписывающем регулировании), а главным образом в том, чтобы устанавливать и

\footnotetext{
${ }^{4}$ Терещенко Л.К. Информация в обществе: правовой аспект// Журнал российского права. 1998. №4/5. С.128.

${ }_{5}^{5}$ Монахов В.Н. Государственно-правовые вопросы информационного обслуживания граждан в СССР (конституционный аспект): Автореф...дис. канд. юрид. наук. М., 1983. С.15-16

${ }^{6}$ Алексеев С.С. Восхождение к праву. Поиск и решения. М., 2001. - C.321.
}

обеспечивать границы поведения, которое строится на началах свободы и самостоятельности субъектов общественных отношений».

С точки зрения А.В. Малько, правовое ограничение - это правовое сдерживание противозаконного деяния, создающее условия для удовлетворения интересов контрсубъекта и общественных интересов в охране и защите некоторых ценностей; это установленные в праве границы, в пределах которых субъекты должны действовать; это исключение определенных возможностей в деятельности лиц7. Правовые ограничения наряду с правовыми стимулами являются основными средствами правового регулирования, применяемыми во всех отраслях законодательства.

Мы полностью согласны с позициями как С.С.Алексеева, так и А.В.Малько, которые выделяли самую главную цель ограничений прав и свобод, а именно, не допустить произвольного применения права, установить правовые пределы реализации права.

Согласно мнениям ученых, юридические обязанности выступают одной из форм ограничений права. Ограничение, - пишет С.С. Алексеев, - это вопрос не о способах, а об объеме регулирования, о границах, имеющихся у лиц прав, которые характеризуют результат юридического регулирования. Достигается же такой результат <...> путем сужения дозволений, новых запрещений, дополнительных позитивных обязываний.

Ограничения прав в конституционном законодательстве выступают специфическими индикаторами, позволяющими определить степень свободы и защищенности личности, соблюдения баланса интересов личности, общества и государства.

Учитывая сказанное, под правовыми ограничениями или ограничениями права, на наш взгляд, обоснованно понимать правовые нормы, непосредственным результатом которых является уменьшение правовых возможностей (объема прав) самостоятельного, свободного (по своему усмотрению) совершения субъектом действий (или воздержания от них) по осуществлению соответствующих прав и свобод.

Итак, какое бы толкование ни придавалось данному понятию, важно отметить следующее: оно всегда вовлечено в правовую форму, то есть всегда имеет форму выражения в виде конкретной нормы права.

Нельзя не отметить, что согласно Федеральному закону «Об обеспечении доступа к информации о деятельности государственных органов и органов

\footnotetext{
${ }^{7}$ Малько А.В. Стимулы и ограничения в праве. Теоретико-правовой аспект. Саратов. 1994. - С. 60-61.
} 
местного самоуправления» доступ пользователей к информации о деятельности государственных органов и органов местного самоуправления обеспечивается различными способами: посредством ее обнародования (опубликования) в средствах массовой информации (ст.12), размещения в сети Интернет (ст.ст.13 и 14), размещения такой информации в помещениях, занимаемых этими органами, и иных отведенных для этих целей местах (ст.16) и т.д.

Однако имеющееся законодательство до настоящего времени не может в полной мере регулировать правоотношения, возникающие по поводу доступа к информации о деятельности органов государственной власти и местного самоуправления. Практика показывает, что существует проблема неэффективности оказания гражданам государственных услуг посредством современных информационных технологий, которая обусловлена недостаточностью практического опыта высокоэффективного электронного информационного взаимодействия и отсутствием регулирования процессов электронного документооборота рамочным нормативным документом.

С целью восстановления своих нарушенных прав на доступ к информации, люди стали чаще обращаться в прокуратуру, в суд с заявлениями об обжаловании действий как государственных органов и органов местного самоуправления, так и их должностных лиц, что, несомненно, создало некий контроль, осуществляемый гражданами за органами государственной власти и местного самоуправления при реализации последними своих полномочий. Указанный контроль не всегда действенен без реально существующей и работающей ответственности, что позволяет компетентным государственным органам нарушать конституционное право на информацию ${ }^{8}$.

Несмотря на то, что в ст.46 Конституции России закреплен принцип защиты доступа к информации посредством установления гарантии его судебной защиты, проведенным анализом законодательства мы установили, что в настоящее время недостаточно урегулирован вопрос обжалования действий должностных лиц в судебном порядке в случае отказа в доступе к информации, предоставления недостоверной информации, а равно предоставления доступа к информации в неполном объеме. Кроме того, отсутствует реально действующий механизм привлечения должностных лиц к ответственности

${ }^{8}$ Погорелова М.А. Конституционно-правовое регулирование права на информацию в Российской Федерации : диссер. ... канд.юрид. наук.М., 2010. С.86. за нарушение права на доступ к информации. Для устранения пробела законодательства в указанной сфере нами предлагается внести изменения в Гражданский процессуальный кодекс Российской Федерации, Федеральный закон «О прокуратуре Российской Федерацией», связанные с порядком разрешения обращений граждан, обжалующих нарушенное право на информацию со стороны должностных лиц органов власти, органов местного самоуправления в суд общей юрисдикции, а также связанные с механизмом привлечения указанных должностных лиц к административной ответственности по ст.5.39 Кодекса Российской Федерации об административных правонарушениях.

Так, в настоящее время процедура обжалования действий (бездействия) органов государственной власти, органов местного самоуправления, должностных лиц, государственных и муниципальных служащих установлена гл.25 Гражданского процессуального кодекса Российской Федерации. В связи с тем, что прокурор наделен правом на проведение проверок на наличие либо отсутствие в действиях должностного лица состава административного правонарушения, предусмотренного ст.5.39 Кодексом Российской Федерации об административных правонарушениях, необходимо внести изменения в ч. 3 ст.45 и ч.1 ст. 257 Гражданского процессуального кодекса Российской Федерации в части состава лиц, участвующих в судебном заседании, а также наделения прокурора правом на предоставление заключения по делу о защите права человека и гражданина на информацию.

Кроме того, для расширения полномочий прокурора в сфере надзора за исполнением законов необходимо внести изменения в ст.22 Федерального закона «О прокуратуре Российской Федерации» в части истребования заключения органов Роспотребнадзора как органов, наделенных полномочиями в проведении проверок в сфере защиты прав потребителей, на наличие либо отсутствие в действиях должностных лиц нарушений порядка, сроков, объема раскрытия информации, а также внести изменения в ч.3 ст.22 в части наделения прокурора правом выносить постановления о возбуждении дела об административном правонарушении, предусмотренном ст.5.39 Кодексом Российской Федерации об административных правонарушениях при установлении нарушения порядка, сроков, объема предоставления информации со стороны уполномоченных лиц вступившим в законную силу решением суда.

Проанализировав судебную практику нами установлено, что в настоящее время совершенно отсутствуют решения суда, по которым должностные лица 
DOI: $10.7256 / 1811-9018.2013 .11 .9677$

При цитировании этой статьи сноска на dоі обязательна

\section{Право и политика $11(166) \cdot 2013$}

органов прокуратуры привлечены к ответственности за нарушение порядка раскрытия информации, предусмотренной ст.5.39 Кодексом Российской Федерации об административных правонарушениях.

В связи с изложенным, нами предлагается внести изменения в гл.25 Гражданского процессуального кодекса Российской Федерации, предусматривающую процедуру обжалования действий (бездействия) органов государственной власти, органов местного самоуправления, должностных лиц, государственных и муниципальных служащих, в том числе прокурора, а именно, включить отдельную статью, предусматривающую процедуры рассмотрения заявлений граждан на обжалование действий либо бездействия тех или иных должностных лиц. В указанную статью в обязательном порядке необходимо включить норму, предусматривающую рассмотрение заявления гражданина по существу в течение 30 дней с момента назначения судебного заседания к рассмотрению, обязательность привлечения к участию в деле того должностного лица, действия которого обжалуются, а также направление решения суда, вступившего в законную силу, вышестоящему должностному лицу для решения вопроса о привлечении должностного лица, нарушившего закон, к установленной ответственности.

Для последующего развития конституционного права на информацию, решения проблем с доступом граждан к информации, а также с неправомерным его ограничением, необходимо принятие базового Федерального закона «О праве на информацию». Указанный закон будет системно регулировать рассматриваемые отношения, устанавливать не только принципы правового регулирования конституционного права на информацию, правореализации такой его формы как доступ к информации, но и устанавливать гарантии реализации права на доступ к информации, раскрывать отдельные правомочия по осуществлению конституционного права на информацию, предусматривать ответственность за их нарушение.

В качестве понимания гарантий реализации конституционного права на информацию, а именно такой его формы реализации как доступ к информации, мы предлагаем использовать данное Д.В.Гавришовым в своем диссертационном исследовании определение 9

Так, автором под гарантиями доступа к информации понимается опосредованный объективными усло-

\footnotetext{
9 Гавришов Д.В. Гарантии реализации субъективного права на информацию: конституционно-правовой аспект: дисс. ... канд. юрид.наук. Белгород. 2010. С.86.
}

виями (экономическими, политическими, социальными и культурными) конкретного государства комплекс юридических возможностей, средств и факторов, позитивно влияющих на реализацию исследуемого права, а также направлений деятельности публичных структур и институтов гражданского общества по его защите и восстановлению.

Данное понятие в наибольшей степени раскрывает содержание исследуемой формы реализации конституционного права на информацию, является перспективным в своем развитии и соответствует тенденциям современности.

Рассматривая вопрос об устранении существующей пробельности конституционного права на информацию, нами предлагается в концепцию закона включить 10 разделов: общие положения (пределы действия права, основные понятия, принципы правового регулирования), гарантии реализации права на информацию, право на получение информации посредством доступа, право поиска, выбора и сбора информации, право использования информации, право распространения информации и право производства информации, ограничения правомочий по осуществлению права на информацию, ответственность за нарушение права на информацию, заключительные и переходные положения.

В текст указанного закона необходимо включить определения как самого конституционного права на информацию, так и всех правомочий по его реализации или форм осуществления права. За основу определения доступа к информации нами предлагается понимать одну из форм реализации конституционного права на информацию путем получения информации о деятельности государственных органов и органов местного самоуправления из открытых и общедоступных источников, а также путем направления запроса и получения на него ответа, при условии соблюдения ограничений, установленных законодательством России.

Из текста данного закона, с учетом предлагаемой концепции, будет видна основополагающая роль конституционного права на информацию во всей системе прав и свобод нашего государства, прежде всего установленных Конституцией России. Данное право получит большую актуальность и будет выступать в качестве базового для возникновения разнообразных форм и многочисленных способов реализации правоотношений во всех сферах деятельности человека и гражданина, в том числе, посредством реализации наиболее важной такой его формы как доступ к информации.

Отмечая необходимость принятия данного закона, Конституционный суд Российской Федерации в при- 
нимаемых им решениях указывал, что до принятия федерального закона, который мог бы урегулировать процедуру проверок при осуществлении прокурорского надзора за исполнением законов, в частности, предусмотреть гарантии прав личности, в том числе права, вытекающего из ст. 24 (ч. 2) Конституции Российской Федерации, и его допустимые ограничения в сфере прокурорского надзора, одно лишь положение п. 2 ст. 5 Федерального закона «О прокуратуре Российской Федерации» не может служить основанием для отказа в предоставлении гражданину возможности ознакомиться с непосредственно затрагивающими его права и свободы материалами прокурорских проверок ${ }^{10}$.

Однако, до настоящего времени, каких-либо нормативно-правовых актов на этот счет не принято, изменений в Федеральный закон «О прокуратуре Российской Федерации», Федеральный закон от 9 февраля 2009 г. N 8-Ф3 «Об обеспечении доступа к информации о деятельности государственных органов и органов местного самоуправления» в этой части внесено также не было.

Анализируя изложенное, можно отметить, что в последнее десятилетие в России наблюдается положительная тенденция в обеспечении конституционного права на информацию о деятельности государственных органов и органов местного самоуправления и в первую очередь через доступ к информации. В этой связи важно продолжать создавать общие механизмы реализации права человека и гражданина на информацию, а также общие механизмы его защиты, к которым, например, можно отнести, положения ч.3 ст.46 Конституции России, устанавливающей право каждого на обращение в международные органы по защите прав и свобод человека, если исчерпаны все имеющиеся внутригосударственные средства правовой защиты.

Однако для решения проблем правового регулирования, в том числе по вопросу порядка обеспечения доступа к информации, контроля за порядком и сроками размещения государственными органами и органами местного самоуправления информации, установления форм контроля и надзора за обеспечением доступа к информации о деятельности государственных органов и органов местного самоуправления необходимо принятие Федерального закона «О праве на информацию», а предложенные нами изменения федерального законо-

\footnotetext{
${ }^{10}$ Постановление Конституционного Суда Российской Федерации от 18 февраля 2000 г. N 3-П по делу о проверке конституционности пункта 2 статьи 5 Федерального закона «О прокуратуре Российской Федерации» в связи с жалобой гражданина Б.А. Кехмана»// Собрание законодательства РФ. 2000. N 9. Ст. 1066.
}

дательства о порядке доступа к информации, об установлении ответственности за нарушение конституционного прав на информацию являются необходимостью времени, поскольку существующее законодательство не позволят решать проблемы правового регулирования доступа к информации, в результате чего происходит нарушение прав и свобод граждан.

Несомненно, в настоящее время остается то обстоятельство, что Конституция нашей страны содержит в себе достаточно полный и прочный «каркас» конституционного права на информацию и его основных правомочий, который частично уже развернут, а частично его еще предстоит развернуть в принимаемом и действующем законодательстве.

\section{Библиография:}

1. Алексеев С.С. Восхождение к праву. Поиск и решения. М., 2001.

2. Бачило И.Л. Информационное право: актуальные проблемы теории и практики: колл.монография.М., 2009.

3. Гавришов Д.В. Гарантии реализации субъективного права на информацию: конституционно-правовой аспект: дисс. ... канд.юрид.наук. - Белгород. 2010.

4. Малько А.В., Исаков Н.В., Субочев В.В. Правовая политика в урегулировании лоббизма.Саратов. 2003.

5. Малько А.В. Стимулы и ограничения в праве. Теоретико-правовой аспект. Саратов. 1994.

6. Монахов В.Н. Государственно-правовые вопросы информационного обслуживания граждан в СССР (конституционный аспект): Автореф...дис. канд. юрид. наук. М., 1983.

7. Погорелова М.А. Конституционно-правовое регулирование права на информацию в Российской Федерации : диссер. ... канд.юрид.наук.М., 2010.

8. Подмарев А. А. Конституционные основы ограничения прав и свобод человека и гражданина в Российской Федерации: дисс. ... канд. юрид. наук. Саратов. 2001.

9. Терещенко Л.К. Информация в обществе: правовой аспект//Журнал российского права. 1998. №4/5.

10. Коновалов А.О. Актуальные проблемы защиты нарушенного права на доступ к информации о деятельности судов в Российской Федерации // NB: Вопросы права и политики.-2013.-7.-С. 100-124. URL: http://www.e-notabene.ru/lr/article_9008.html 
DOI: $10.7256 / 1811-9018.2013 .11 .9677$

При цитировании этой статьи сноска на доі обязательна

\section{Право и политика $11(166) \cdot 2013$}

\section{References (transliteration):}

1. Alekseev S.S. Voskhozhdenie k pravu. Poisk i resheniya. M., 2001.

2. Bachilo I.L. Informatsionnoe pravo: aktual'nye problemy teorii i praktiki: koll.monografiya.M., 2009.

3. Gavrishov D.V. Garantii realizatsii sub"ektivnogo prava na informatsiyu: konstitutsionno-pravovoi aspekt: diss. ... kand.yurid.nauk. - Belgorod. 2010.

4. Mal'ko A.V., Isakov N.V., Subochev V.V. Pravovaya politika v uregulirovanii lobbizma.Saratov. 2003.

5. Mal'ko A.V. Stimuly i ogranicheniya v prave. Teoretiko-pravovoi aspekt. Saratov. 1994.

6. Monakhov V.N. Gosudarstvenno-pravovye voprosy informatsionnogo obsluzhivaniya grazhdan v SSSR (konstitutsionnyi aspekt): Avtoref...dis. kand. yurid. nauk. M., 1983.

7. Pogorelova M.A. Konstitutsionno-pravovoe regulirovanie prava na informatsiyu v Rossiiskoi Federatsii : disser. ... kand.yurid.nauk.M., 2010.

8. Podmarev A. A. Konstitutsionnye osnovy ogranicheniya prav i svobod cheloveka i grazhdanina v Rossiiskoi Federatsii: diss. ... kand. yurid. nauk. Saratov. 2001.

9. Tereshchenko L.K. Informatsiya v obshchestve: pravovoi aspekt//Zhurnal rossiiskogo prava. 1998. №4/5.

10. Konovalov A.O. Aktual'nye problemy zashchity narushennogo prava na dostup $\mathrm{k}$ informatsii o deyatel'nosti sudov v Rossiiskoi Federatsii // NB: Voprosy prava i politiki.-2013.-7.-C. 100-124. URL: http://www.e-notabene.ru/lr/article_9008.html 